\title{
Single coronary artery: anomalous origin of right coronary artery from the left anterior descending artery
}

\author{
Satish Karur, Soumya Patra, Ravindranath K Shankarappa, Navin Agrawal
}

Deapartment of Cardiology, Sri Jayadeva Institute of Cardiovascular Sciences \& Research, Bangalore, Karnataka, India

\section{Correspondence to}

Dr Navin Agrawal, drnavinagrawal@gmail.com
To cite: Karur S, Patra $S$, Shankarappa RK, et al. BMJ Case Rep Published online: [please include Day Month Year] doi:10.1136/bcr-2013200548

\section{DESCRIPTION}

We are presenting an interesting case of a single coronary artery in a patient presenting with an acute coronary event. A 33-year-old man presented with an acute anterior wall myocardial infarction and was lysed with streptokinase. He subsequently underwent coronary angiography which revealed the presence of only a single coronary artery.

The left main coronary artery (LMCA) was dividing into the left anterior descending (LAD) and the left circumflex coronary artery (LCX) and there was a left dominant circulation (figure 1). Interestingly, there was an anomalous origin of the right coronary artery (RCA) from the proximal LAD which had a proximal stenosis of around 60$70 \%$ severity at its origin (figures $1-3$ ). The finding was also confirmed by an aortic root angiogram (figure 4). The case was planned for conservative treatment because the patient was asymptomatic and there was no evidence of any ischaemia in the inferior wall territory. Conservative treatment was also justified in this case as the lesion was not critical and was present in a non-dominant artery. The patient also had a thrombus containing lesion in the LMCA, proximal LAD and LCX which was managed conservatively with intravenous glycoprotein IIb-IIIa inhibitor infusion. The lesion was predominantly thrombus containing with less atheromatous quotient with good antegrade flow as was confirmed in other views. Hence, stent deployment

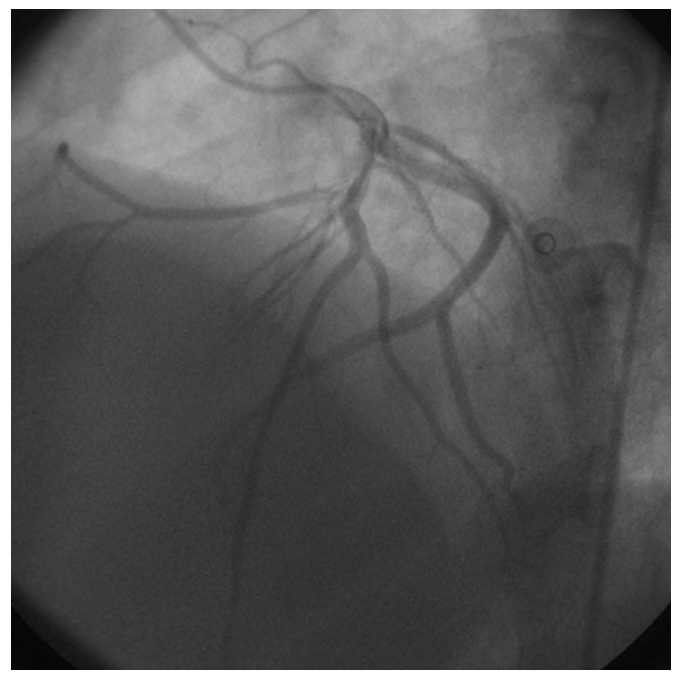

Figure 1 Left anterior oblique-cranial view showing anomalous origin of right coronary artery from proximal left anterior descending which has $20-30 \%$ stenosis and dominant left circumflex coronary artery.

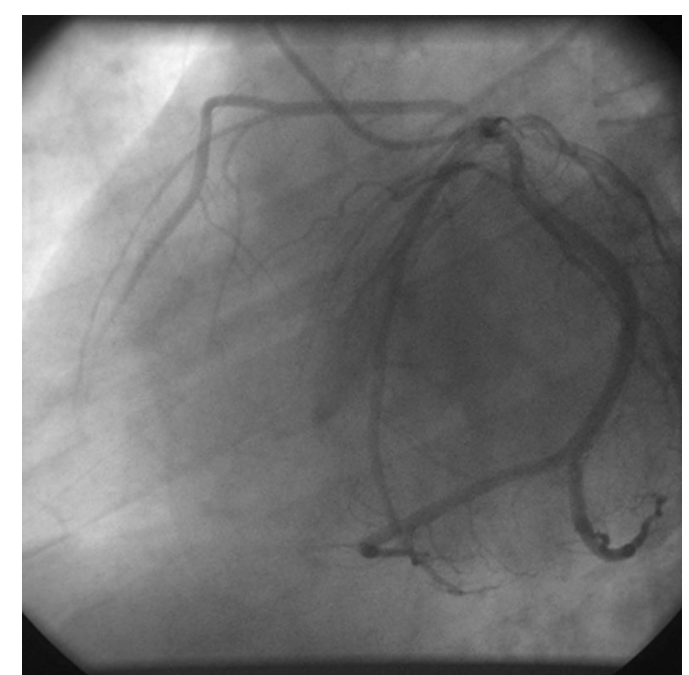

Figure 2 Left anterior oblique -caudal view showing origin of right coronary artery from left anterior descending with coursing towards its familial area.

in this lesion was not considered for fear of thrombus migration and no-reflow phenomenon leading to a fresh infarct in a patient who was presently asymptomatic.

Congenital anomalies of coronary arteries are very rare and usually documented as an incidental finding during routine catheter or CT angiograms

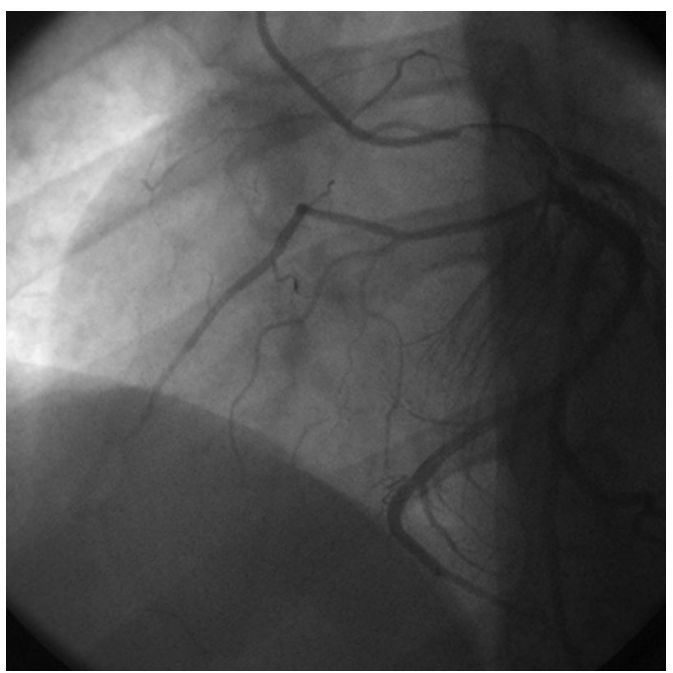

Figure 3 Coronary angiography showing the course of right coronary artery in right atrioventricular groove and its continuation. Proximal left main coronary artery and left anterior descending had a thrombus containing lesion with good antegrade flow. 


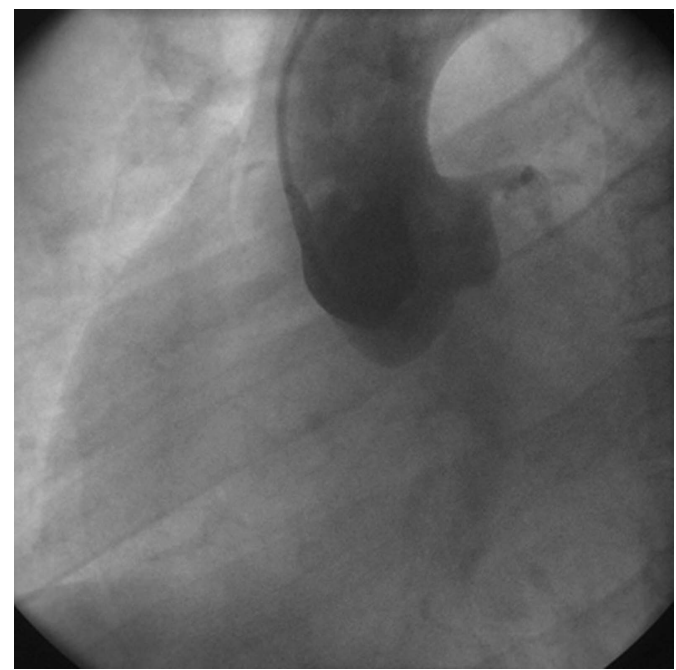

Figure 4 Aortic root angiogram revealed single coronary artery from left aortic sinus.

performed for other reasons. ${ }^{1}$ A review of the literature reveals RCA originating from the LAD is extremely rare with an approximate incidence of $0.024 \%$ in the general population. ${ }^{2}$

The incidence of anomalous RCA has been reported to be the highest in the Indian subcontinent. ${ }^{3}$ Anomalous RCA after originating from the left system often courses along the anterior wall of the right ventricle or sometimes it courses between the pulmonary trunk and ascending aorta where its compression can lead to arrhythmias and sudden death and is also prone for atherosclerosis due to tortuosity.

\section{Learning points}

- Single coronary artery has an approximate incidence of $0.024 \%$ of the general population.

- This rare occurrence of coronary anomaly is a clinically significant event as it can lead to acute coronary syndrome due to the accelerated atherosclerosis seen in these vessels due to their tortuosity. They also are a potential cause of sudden cardiac death is young.

- CT coronary angiogram is the investigation of choice to diagnose coronary artery anomaly.

\section{Competing interests None.}

Patient consent Obtained.

Provenance and peer review Not commissioned; externally peer reviewed.

\section{REFERENCES}

1 Zhu J, Xiong W, Xuguang Q. Single coronary artery anomaly: right coronary artery originating from the mid left anterior descending artery. J Invasive Cardiol 2011;23:258-60.

2 Xuguang Q, Xiang W, Lu C. The coronary anomaly: right coronary artery originates from the mid left anterior descending artery. J Invasive Cardiol 2010;22:E166-7.

3 Agarwala $\mathrm{R}$, Kapoor $\mathrm{A}$. The mystery of the lost and found right coronary artery. Catheter Cardiovasc Interv 2010;76:969-72.

Copyright 2013 BMJ Publishing Group. All rights reserved. For permission to reuse any of this content visit

http://group.bmj.com/group/rights-licensing/permissions.

BMJ Case Report Fellows may re-use this article for personal use and teaching without any further permission.

Become a Fellow of BMJ Case Reports today and you can:

- Submit as many cases as you like

- Enjoy fast sympathetic peer review and rapid publication of accepted articles

- Access all the published articles

- Re-use any of the published material for personal use and teaching without further permission

For information on Institutional Fellowships contact consortiasales@bmjgroup.com

Visit casereports.bmj.com for more articles like this and to become a Fellow 